\title{
Sex on the Brain or the Sexual Self-Consciousness as Essential Factor Influencing Cognitive Performance of Older People?
}

\author{
Andrzej Brodziak ${ }^{1}$, Alicja Różyk - Myrta ${ }^{2}$, Estera Kołat ${ }^{2 .}$ \\ ${ }^{1}$ Institute of Occupational Medicine and Environmental Health, Sosnowiec, Poland \\ http://www.imp.sosnowiec.pl/ english/ \\ ${ }^{2}$ Institute of Nursing, University of Applied Sciences, Nysa, Poland \\ http://www.universitynysa.cn/index.php \\ andrzejbrodziak@wp.pl
}

\begin{abstract}
The authors comment some recent articles on the detected positive associations between sexual activity and results of tests of cognitive performance achieving by older people. They indicate the data collected in the course of "Wave 6" of The English Longitudinal Study of Ageing (ELSA). These investigations demonstrated, that however the level of sexual activity declines with increasing age, although a sizable minority of men and women remain sexually active until the eighth and ninth decades of life.

The authors of the article consider what makes these women and men that they remain sexually active in their 70 s and 80s. They point out that perhaps attempt to answer to this question may be based on results obtained previously, which revealed that the unfavorable cognitive functioning of older people was associated with perceiving sexuality as unimportant and with evaluating sexual life as unpleasant.

So, it seems that there should be an attempt to formulate a scale, which would be related to the positive attitude towards sexuality. The authors proposed therefore a short list of manifestations of this special attitude. They named their 10 points list as a "body awareness, sensuality and libido scale". The elements of this list are settled in a arbitrary, intuitive way, but the authors began the trials of its validation.
\end{abstract}

Keywords: sexual activity, cognitive performance, body awareness, sensuality, libido scale.

Keypoints: 1. The positive association is found between sexual activity and cognitive performance among older people. 2. Some researchers revealed that the unfavorable cognitive functioning of older people was associated with perceiving sexuality as unimportant and with evaluating sexual life as unpleasant. 3. There are the need to formulate the scale for assasment of the body awareness, sensuality, libido.

\section{Text of the article:}

Recently we would like to publish the paper sub title: "The trial of the evaluation of the sexual selfconsciousness of older people". The reviewer wrote that: "Title does not make sense", but among other remarks he indicated the paper, which really was missing among our reference publications, it means the article of Hayley Wright and Rebecca A. Jenks entitled: "Sex on the brain! Associations between sexual activity and cognitive function in older age"[1]. The authors of this article take advantage of data collected in the course of "Wave 6" of the English Longitudinal Study of Ageing (ELSA), a nationally representative panel survey that gathers data on health, lifestyle and socioeconomic variables in adults over the age of 50 years. The questionnaire for the cohort "Wave 6 of ELSA" includes first time the questions pertaining to sexual relationships, and therefore enable the investigation of associations between sexual activity and cognitive function of older people.

The authors of the quoted article selected from many questions of the used Sexual Relationships and Activities Questionnaire (SRA-Q), only a simple specific criterion enabling to distinguish older adults who were sexually active from those who were not. They assumed that sexual activity could include: intercourse, masturbation, petting or fondling. The dependant variables in this study were scores from cognitive tests of recall and a number sequencing. In the recall task, respondents heard a list of 10 everyday words and were asked to recall them immediately away and after a short delay. Wrigh et al. found that "there were significant associations between sexual activity and number sequencing and recall in men". The authors assumed that these parameters are good enough measurements of cognitive performance. They argue that "sexual activity is associated with higher scores on tests of memory and executive function, in adults aged $50-89$ ". 
These authors are convinced that their findings have "important implications for the inclusion of sexual health discussions during routine health checks for over 50s and for the provision of sexual counseling in this age group". According to them it could provide "a benefit to cognitive function in older adults".

Data obtained during the "Wave 6" of the ELSA study, were also utilized by Lee et al [2]. They estimated the overall sexual activity, problems with sexual functioning, and concerns about sexual health among all 7079 persons, who completed the SRA-Q. They found that however the level of sexual activity declines with increasing age, although a sizable minority of men and women remain sexually active until the eighth and ninth decades of life. These authors conclude similarly, that "health professionals should be open to discussing sexual health concerns with older adults and proactive in offering treatment and counseling to maximize sexual health and well being".

The question arises however, what makes these women and men that they remain sexually active in their 70s and 80s. Of course, there are the impacts of state of health, circumstance of having a partner, and other existential prerequisites. These relationships are quite precisely recognizes in the work of Lee et al. [2] and Hartmann et al. [3].

It seems to us, however, that important is the level of sensuality, which is formed from the earliest life years $[4,5,6,7]$.In the terminology of psychology this factor was recognized as the concept of so called "libido". This conviction results also from recent research data.

Hartmans et al. investigated whether cognitive functioning is associated with the perception of one's sexuality in old age [8]. They assessed sexuality and intimacy by concrete four questions and some cognitive domains using Mini-Mental State Examination, as well as test of memory performance (Auditory Verbal Learning Test), processing speed (Coding Task), and fluid intelligence (Raven's Coloured Progressive Matrices). They found that: lower fluid intelligence and lower general cognitive functioning was associated with perceiving sexuality as unimportant; and lower immediate memory recall was associated with evaluating sexual life as unpleasant. Lover cognitive parameters were related also with disagreeing with a remaining need for intimacy when getting older. So, higher cognitive functioning of older people is associated with the way in which they perceived the sexuality as a value.

Thompson et al. tried to determine if measures of "successful-aging are associated with sexual activity, satisfaction, and function in older post-menopausal women". They performed cross sectional study and found that such manifestations of sexual activity as desire, arousal, vaginal tightness, use of lubricants, and ability to climax - were negatively associated with age, as were physical and mental health. In contrast, sexual satisfaction and self-rated successful aging and quality of life remained unchanged across age groups. It was found that successful aging measures were positively associated with sexual measures, especially self-rated quality of life and sexual satisfaction. Self-rated successful aging, quality of life, and sexual satisfaction occurred to be stable in the face of declines in physical health. The cognitive abilities, and sexual activity were positively associated from age 60 to 89 [9].

So, not only real sexual activity is important, but just its evaluation. It seems to us that there should be attempts to formulation of a scale, which would be related to this positive attitude towards sexuality. Such a scale should determine just how sex is "on the brain", how it is imprinted in our head.

Taking into account the statements of Hartmans et al. that "sex on the brain" should be "important", and findings of Thompsonet al. that sexual satisfaction "remained unchanged" through decades, we proposed a short list of manifestations of this special attitude. We named this 10 points list as a "body awareness, sensuality and libido scale". It is presented in Table I. The elements of this list are settled in a arbitrary, intuitive way and of course this scale should be validated. The problem is however, what could be the criterion of such validation.

The difficulties in the process of the validations of scales measuring sexual activity and sexual attitudes is discussed by some authors $[10,11,12,13,14]$. More difficult than measuring sexual activity are problems with formulation of the tools assessing the attitude of sensuality and sources of interest in sex. Katie McCall and Cindy Meston try to approach this subject [14].

So far we have managed to juxtapose responses to the item of this scale obtained in the 56 person group of elderly women and a group of 20 younger women. The survey was carried out among: (1) 
the participants of so called University of Third Age in Nysa (South of Poland) and (2) students at the University of Applied Sciences in Nysa realizing the master degree study in nursing.

The range of age in the group of older women was $<60-81>$, mean age 69,1 standard deviation 6,2 and the same data for the group of younger women was $<24-49>$, mean age 36,35, standard deviation 7.19. The proportion of answer for our proposed scale of "body awareness, sensuality and libido" is presented in the Table I.

Table1.The content of the proposed scale of \{body awareness, sensuality and libido\} (column 2) and proportions of answer "yes" to items of this scale in percentages (rounded values) in the examined groups of older and younger women. The additional rows, designed as A, $B$ and $C$ give the proportions of the answers (in percentages, rounded values) to the questions related to the real, actual sexual activity.

\begin{tabular}{|c|c|c|c|}
\hline No & Statements related to body awareness, sensuality and libido & $\begin{array}{c}\text { Answer } \\
\text { "Yes" } \\
(\%) \\
\text { in the } \\
\text { older } \\
\text { group }\end{array}$ & $\begin{array}{c}\text { Answer } \\
\text { "Yes" } \\
(\%) \\
\text { in the } \\
\text { younger } \\
\text { group }\end{array}$ \\
\hline 1 & I accept fully my body & 58 & 50 \\
\hline 2 & $\begin{array}{c}\text { As a woman - I dress to look sexy; being a man I admit that I pay attention to } \\
\text { dress and appearance of sensuality of women }\end{array}$ & 46 & 78 \\
\hline 3 & Erotic life, sex has always been important to me & 41 & 55 \\
\hline 4 & $\begin{array}{l}\text { I accept sensuality, I perceive sexuality in myself and other people and in } \\
\text { heroes of novels and movies }\end{array}$ & 37 & 70 \\
\hline 5 & $\begin{array}{l}\text { I lik I like to read articles about sex and watch } \\
\text { Erotic videos }\end{array}$ & 7 & 40 \\
\hline 6 & $\begin{array}{l}\text { I don't care the various objections in face of } \\
\text { sensuality and sex, coming from the clergy } \\
\text { and various moralists }\end{array}$ & 28 & 42 \\
\hline 7 & I treat the erotic life and sex as a reward for the life effort & 7 & 14 \\
\hline 8 & I think my sensuality is higher than average & 7 & 28 \\
\hline 9 & $\begin{array}{c}\text { As a woman I act so that - in a discreet and elegant manner I inspire male } \\
\text { desire. Being a man I behave to increase potential opportunity to get to know } \\
\text { women. }\end{array}$ & 23 & 92 \\
\hline 10 & I use the erotic imagery very often & 23 & 28 \\
\hline & Sum o points & & 5,6 \\
\hline A & My sexual activity is rich and satisfies me & 30 & 60 \\
\hline B & My sexual activity is scarce and does not satisfy me & 30 & 30 \\
\hline $\mathbf{C}$ & No answer & 40 & 10 \\
\hline
\end{tabular}

The mean number of points determined by the proposed scale for the "sexual consciousness" in the group of older women was 3,01 (standard deviation 1,78) and in the reference group of 20 young women was 5,6 (standard deviation 1.39).

So, it can be shown that the intensity of \{ "body awareness, sensuality and libido" $\}$ is significantly different between older and younger women. It can be also shown that among older people there is a significant proportion of women who still have high values on the scale of "body awareness, sensuality and libido".

It can be also shown that people with high values at that scale do have more frequent and satisfying sexual activity than those with low values on this scale. Previously quoted authors argued for the existence of a positive correlation between sexual activity and mental performance. Of course, it remains yet to investigate if older people, who are sexually active and have high "libido" are more effective in cognitive tasks.

It is also important whether the factors that make up the proposed scale are prone to modifications and if is possible that some people could intensify this \{body awareness, sensuality and libido\}?

Both teams of Wright et al. and Lee et al. postulated, however, that the medical staff should include to their talks with older patients elements of "sexual counseling". What would be the content of those conversations? It seems to us that the content of such discussions, counseling and advices could be based on mental processes and attitudes which we describe in our list constituting the proposed scale of "libido". 


\section{REFERENCES}

[1] Wright H., Jenks R.A. Sex on the brain! Associations between sexual activity and cognitive function in older age. Age Ageing. 2016 Mar;45(2):313-7.doi: 10.1093/ageing/afv197

[2] Lee DM, Nazroo J, O'Connor DB, Blake M4, Pendleton N5. Sexual health and well-being among older men and women in England: Findings from the English Longitudinal Study of Ageing. Arch Sex Behav. 2016 Jan;45(1):133-44. doi: 10.1007/s10508-014-0465-1.

[3] Hartmann U, Philippsohn S., Heiser K., Ruffer - Hesse C. Low sexual desire in midlife and older women: personality factors, psychosocial development, present sexuality. Menopause, 2004; 11(6 Pt 2): 726-40.

[4] Meana M. Elucidating women's (hetero)sexual desire: definitional challenges and content expansionJ Sex Res., 2010; 47(2): $104-22$.

[5] Stark R, Kagerer S, Walter B, Vaiti D, Klucken T, Wehrum - Osinsky S. Trait sexual motivation questionnaire: concept and validation. J Sex Med 2015; 12: 1080 - 91.

[6] Simon JA, Low sexual --is it all in her head? Pathophysiology, diagnosis, and treatment of hypoactive sexual desire disorder. Postgrad Med 2010; 122:128-36.

[7] Davison Sl. Hypoactive sexual desire disorder. Curr Opin Obstet Gynecol 2012; 24: 215-20.

[8] Hartmans C, Comijs H, Jonker C. The perception of sexuality in older adults and its relationship with cognitive functioning. Am J Geriatr Psychiatry. 2015 Mar; 23(3):243-52.

[9] Thompson WK, Charo L, Vahia IV, et al. Association between higher levels of sexual function,activity, and satisfaction and self-rated successful aging in older postmenopausal women. J Am Geriatr Soc. 2011 Aug; 59(8):1503-8.

[10] DeRogatis LR, Allgood A, Auerbach et al. Validation of a Women's Sexual Interest Diagnostic Interview- Short Form (WSID-SF) and a Daily Log of Sexual Activities(DLSA) in postmenopausal women with hypoactive sexual desire disorder. J Sex Med. 2010; 7:917-27.

[11] Toledano R, Pfaus J. The Sexual Arousal and Desire Inventory (SADI) a multidimensional scale to assess subjective sexual arousal and desire. J Sex Med. 2006;3:853-77

[12] Wiegel M, Meston C, Rosen R. The female sexual function index (FSFI): cross-validation and development of clinical cutoff scores. J Sex Marital Ther.2005; 31:1-20.

[13] Rosen RC, Lobo RA, Block BA, Yang HM, Zipfel LM. Menopausal Sexual Interest Questionnaire (MSIQ): a unidimensional scale for the assessment of sexual interest in postmenopausal women. J Sex Marital Ther. 2004; 30:235-50.

[14] McCall K, Meston C. Cues resulting in desire for sexual activity in women. J Sex Med. 2006; 3:838-52. 